\#009 Tratamento endodôntico microcirúrgico de defeitos ósseos classe F - Série de 13 casos CrossMark

Abayomi O Baruwa, Mariana Domingos Pires*, Ana Beatriz de Cristino Roque Jordão Pereira, Jorge NR Martins, Pedro Cruz, António Ginjeira

Faculdade de Medicina Dentária da Universidade de Lisboa (FMDUL)

Introdução: O objetivo da microcirurgia endodôntica é a eliminação de infeção peri-radicular persistente quando o retratamento não cirúrgico não é aconselhável ou exequível. Com elevadas taxas de sucesso associadas, tem vindo a ganhar popularidade enquanto opção terapêutica. No entanto, nos casos com doença periodontal concomitante, a presença de defeitos ósseos verticais aumenta a complexidade do tratamento, implicando muitas vezes a utilização de materiais de substituição ósseos. Nesta série apresentamos 13 casos classificados como classe F de Kim et al. (2006) abordados micro-cirurgicamente, com controlos até 9 anos. Descrição do caso clínico: Os procedimentos clínicos foram semelhantes em todos os casos, realizados pelo mesmo clínico sob ampliação com microscópio ótico. Após anestesia infiltrativa foram efetuados retalhos triangulares com incisão 'papilla-based', osteotomia para acesso à região periapical e apicectomia não biselada de pelo menos $3 \mathrm{~mm}$. A retro-preparação foi feita com recurso a pontas de ultrassons e, após secagem dos canais, foi aplicado MTA para retro-obturação. O material de enxerto ósseo foi autologo, recolhido da zona da intervenção, ou xeno-enxerto bovino, cobertos por uma membrana reabsorvível de colagénio colocada pelo menos $2 \mathrm{~mm}$ para la de toda a margem da loca. Os tecidos foram reposicionados com suturas, removidas ao fim de 5/7 dias. Efetuaram-se controlos clínicos 1 mês pós-cirúrgico, e controlos radiográficos a cada 6 meses até à remissão total da lesão. Discussão e conclusões: Todos os casos representados correspondem a abordagens microcirúrgicas bem-sucedidas de defeitos classe F, com lesões endo-perio de origem primária endodôntica, com controlos de 3 a 9 anos. Apesar de alguns estudos relacionarem a existência de defeitos apico-marginais com taxas de sucesso inferiores a $50 \%$ estas poderiam estar relacionadas com a utilização de técnicas de microcirurgia tradicionais, sem recurso a ampliação e sem aplicação de técnicas de regeneração tecidular guiada. Mais recentemente, foram reportadas taxas de sucesso acima de $83 \%$ com a utilização de Bio-Oss como enxerto e Bio-Gide como membrana, semelhante aos resultados obtidos nestes casos. Com um correto diagnóstico e planeamento, existem atualmente técnicas viáveis, e com bom prognóstico, para casos de extensos defeitos periodontais com origem endodôntica. http://doi.org/10.24873/j.rpemd.2022.01.869

\#010 Lesão mandibular num caso de mieloma múltiplo: Uma abordagem multidisciplinar

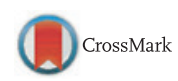

Salomé Cavaleiro*, Rita Martins, Lúcia Vieira, Mariana Moreira

Serviço de Estomatologia do Centro Hospitalar Universitário São João, Serviço de Imunohemoterapia do Centro Hospitalar de Vila Nova de Gaia e Espinho
Introdução: O mieloma múltiplo apresenta um amplo espectro de manifestações clínicas, incluindo lesões ósseas líticas que tipicamente envolvem o esqueleto axial. O atingimento dos ossos maxilares não é incomum, sendo o ângulo e ramo da mandíbula os locais mais frequentemente afetados. A gestão da morbilidade associada a estas situações nem sempre é fácil, exigindo uma abordagem multidisciplinar, como se relata neste caso. Descrição do caso clínico: Um doente do sexo masculino, 52 anos de idade, foi diagnosticado com mieloma múltiplo IgG/kappa (estádio IIIB-SD) com lesões osteolíticas na coluna lombar. Realizou radioterapia lombar (20Gy, 4Gy/dia) e quimioterapia (dexametasona em alta dose, seguida de quatro ciclos de bortezomib/talidomida/dexametasona) com obtenção de resposta completa. Menos de seis meses depois, o doente desenvolveu uma tumefação dolorosa na hemiface esquerda associada a abaulamento intraoral no terceiro quadrante. Foi observado pelo Serviço de Estomatologia, tendo sido requisitada uma tomografia computorizada craniofacial que revelou uma lesão osteolítica de $36 \times 11 \mathrm{~mm}$ no corpo da mandíbula à esquerda e uma massa de $40 \times 28 \mathrm{~mm}$ ocupando os seios esfenoidais, células etmoidais posteriores, cavidade nasal esquerda e seio cavernoso, condicionando reabsorção óssea. Realizou-se uma biópsia da lesão mandibular que mostrou infiltração óssea pelo mieloma múltiplo. Perante o diagnóstico de recidiva precoce e doença extramedular, reiniciou-se radioterapia (30Gy, 3Gy/dia) e quimioterapia com o esquema PACE (2 ciclos). Apesar da diminuição das dimensões da massa sinonasal, a lesão osteolítica mandibular persistiu. Realizou-se escalada terapêutica do esquema de quimioterapia que foi posteriormente suspensa por ausência de resposta. O aumento progressivo da massa mandibular comportou dor intensa e trismo, dificultando a alimentação e causando grande impacto na qualidade de vida. Durante este período foram realizados tratamentos estomatológicos regulares de forma a aliviar a dor orofacial, limitar o risco de infeção local e controlar a hemorragia intraoral. Entretanto o doente foi proposto para cuidados paliativos, vindo a falecer dois anos após o diagnóstico. Discussão e conclusões: Este caso enfatiza as dificuldades que podem estar associadas à abordagem de lesões líticas mandibulares no contexto de mieloma múltiplo, destacando a importância de uma abordagem multidisciplinar desta doença.

http://doi.org/10.24873/j.rpemd.2022.01.870

\section{\#011 Planeamento 3D da distração osteogénica mandibular - Caso clínico}

Flávia da Cunha Pereira*, Inês Alexandre Neves Francisco, Francisco Fernandes do Vale

Instituto de Ortodontia da Faculdade de Medicina da Universidade de Coimbra

Introdução: A retrognatia mandibular grave é, tradicionalmente, corrigida com recurso à cirurgia ortognática através da Osteotomia Sagital Bilateral, na idade adulta. No entanto, em alguns doentes, e pela gravidade da condição clínica, não é desejável esperar pelo término do crescimento do indivíduo para corrigir a deformidade esquelética. Nestes casos o trata- 